\title{
Helicobacter pylori Infection; Immunohistochemical in Hepatic Tissue Biopsies and Serum IgG Antibody of Hepatitis C Virus Infected Patients
}

\author{
Waleed M. Serag ${ }^{1 *}$, Mohamed Hassany ${ }^{2}$, Basem E. Eysa ${ }^{2}$, Ahmed Elhenawy ${ }^{3}$, Samia Gabal $^{3}$, Basma \\ Mohamed $^{4}$, Ehsan Hassan ${ }^{4}$ and Nashwa Zaki ${ }^{5}$ \\ ${ }^{1}$ Chemistry Department, Faculty of Science, Suez University, Egypt \\ ${ }^{2}$ Tropical Medicine Department, National Hepatology \& Tropical Medicine Research Institute (NHTMRI), Cairo, Egypt. \\ ${ }^{3}$ Pathology Department, Cairo University, Cairo, Egypt. \\ ${ }^{4}$ Pathology Department, National Hepatology \& Tropical Medicine Research Institute (NHTMRI), Cairo, Egypt. \\ ${ }^{5}$ Clinical Pathology Department, National Hepatology \& Tropical Medicine Research Institute (NHTMRI), Cairo, Egypt.
}

ARTICLE INFO

Article history:

Received 22 October 2017

Accepted 25 December 2017

Keywords:

$\mathrm{HCV}$;

H. pylori;

CLD;

Cirrhosis.

\begin{abstract}
A B S T R A C T
Hepatitis $\mathrm{C}$ virus (HCV) and Helicobacter pylori (H. pylori) infections are two common global infections; $\mathrm{HCV}$ is associated with a wide spectrum of liver histological lesions ranging from mild chronic hepatitis to cirrhosis and hepatocellular carcinoma. In the current study, the status of $H$. pylori infection was investigated in hepatic tissue biopsies of $\mathrm{HCV}$ infected patients with comparison to serum $H$. pylori $\operatorname{IgG~Ab}$. The material of this study comprised paraffin blocks of hepatic tissue core biopsies from 134 adult patients known to have chronic hepatitis $\mathrm{C}$ virus. All cases were collected from the archive of the pathology department at National Hepatology and Tropical Medicine Research Institute, Cairo. H. pylori $\mathrm{Ab}(\mathrm{IgG})$ were detected in all patients. Fifty five cases (41\%) showed positive $H$. pylori IgG Ab and positive $H$. pylori immunoreactivity in hepatic tissues. It was found that the mild grades of hepatitis showed the highest percent of $\mathrm{H}$. pylori positivity $(56.3 \%)$, followed by the moderate grade $(42.2 \%)$, then the minimal grade $(40.5 \%)$, and lastly the severe grade $(25 \%)$, with no significant difference. Also, early stages of hepatic fibrosis showed higher rate of $\mathrm{H}$. pylori positivity $(44.3 \%)$ than that of the advanced stages $(37.5 \%)$. A relation that didn't reach a significant level, there was a direct proportional relationship between $H$. pylori positivity and the percent of steatosis, a relation that didn't reach a significant level. From the present study, we concluded that $H$. pylori could be detected in the liver tissue of chronic hepatitis C patients; So, investigation of the pathological role of $H$. pylori colonization in the liver tissue of patients with $\mathrm{HCV}$ is an important and valuable task and giving the same results of $H$. pylori $\operatorname{IgG~Ab}$ explaining the role of $H$. pylori $\operatorname{IgG~Ab}$ in dispensing with biopsies.
\end{abstract}

\section{Introduction}

Diagnostic tests of $H$. pylori infection are usually divided into invasive (endoscopic-based) and noninvasive methods. Numerous serological tests based on the detection of anti-H. pylori $\mathrm{IgG}$ antibody are widely available for $H$. pylori diagnosis. Because the accuracy of serological tests depends on the antigen used in commercial kit, specific $H$. pylori strains are employed as the source of antigen. Proper antigens, either using local strains as the source of antigen or

\footnotetext{
* Corresponding author.

E-mail address: waleed.ibrahim@suezuniv.edu.eg
}

pooling antigens from strains of different groups, as well as reliable cutoff value of serological test should be validated locally before investigating population ${ }^{[1,2]}$. The advantage of serological test is that the accuracy of serological tests is not affected by ulcer bleeding, gastric atrophy as well as the use of PPI or antibiotics, which cause false negative results in other invasive or non invasive tests ${ }^{[3]}$.

Many researchers have documented the colonization of Helicobacter pylori (H. pylori) in the human hepatic tissue, investigation of the pathological role of $H$. pylori colonization in the liver tissue of patients with chronic 
hepatitis $\mathrm{C}$ virus (HCV) infection became an important and valuable task, as progress in this area will increase our understanding of the aetiopathology of liver cirrhosis and hepatocellular carcinoma (HCC) ${ }^{[4]}$. It has been shown that Helicobacter spp. could also secrete a liver - specific toxin that causes hepatocyte necrosis in cell culture, and might, therefore, be involved in damaging liver parenchyma in vivo ${ }^{[5]}$. Viruses, including $\mathrm{HCV}$ are capable of inducing limited inflammation ${ }^{[6]}$, while $H$. pylori organisms are potent inducers of the inflammatory cascade ${ }^{[7]}$. Also, it has been shown that $H$. pylori cause proto-oncogene activation that is likely the key step in the pathway of $H$. pylori induced neoplasia ${ }^{[8]}$. However, HCV doesn't integrate into the host DNA and is likely that the mechanism of carcinogenesis differs from that of Hepatitis B virus (HBV). Therefore, the need to clarify the pathogenic effect by which HCV may lead to liver cancer has become of prime importance because the currently known risk factors cannot explain all aspects of its progression to HCC, other causal factors should be identified, whether H. pylori species play a role in the progression towards cirrhosis and carcinogenesis in humans with viral hepatitis is still under review ${ }^{[9]}$. In the current study, the status of $H$. pylori infection was investigated in hepatic tissue biopsies of HCV infected patients with comparison to serum $H$. pylori $\operatorname{IgG~Ab}$.

\section{Materials and methods}

The study was reviewed and approved by Independent Ethics Committees and conducted in accordance with the Declaration of Helsinki and Good Clinical Practice guidelines. All enrolled patients provided written, informed consent prior to the start of the study. 134 adult cases known to have chronic HCV confirmed by $\mathrm{HCV}$ antibody positivity and presence of viral RNA by quantitative PCR, the whole studied population were a part of national treatment program of HCV in Egypt. The mean age of the enrolled group was $43.2 \pm 10.1$ years (mean $\pm \mathrm{SD}), 92$ patients were males $(68.7 \%)$ and 42 patients were females (31.3\%). 37 patients showed minimal chronic hepatitis, 32 showed mild, 33 showed moderate and 32 showed severe chronic hepatitis. 43 patients showed grade 0 steatosis, 81 showed grade 1 and 10 showed grade 2 steatosis. 70 patients showed early stage of fibrosis and 64 patients showed advanced stage of fibrosis. Assessment of liver histology was a crucial step during patients' enrollment to make stratified prioritization of treated patients according to their fibrosis score, the paraffin blocks of hepatic tissue core biopsies were collected from the archive of the pathology department at National Hepatology and Tropical Medicine Research Institute (NHTMRI) during the period between January 2014 and January 2017. Five micron-thick sections were prepared from the paraffin blocks and stained with:

1) Haematoxylin and Eosin $(H \& E)$ stain, for histopathological study and necroinflammatory grading of chronic hepatitis,
2) Masson trichrome stain, a special stain used for collagen detection and staging of fibrosis of the examined slides,

3) Geimsa stain, a special stain, most useful for the demonstration of micro-organisms, like H. pylori,

4) Immunohistochemical staining, specific for $H$. pylori antigen detection.

All cases were reexamined for assessment of necroinflammatory grades and liver fibrosis according to Ishak et al. ${ }^{[10]}$. Steatosis was revised as a mean percentage allover hepatic tissue core biopsy (X-100) and was graded according to Kleiner et al. ${ }^{[11]}$ who grades the steatosis as the following ; <5\% (Grade 0 ), $5 \%$ - 33\% (Grade 1) , 33\% - 66\% (Grade 2) more than $66 \%$ (Grade 3). Visualization of $H$. pylori positive antigen appeared on the cell wall of the infected hepatocytes ${ }^{[12]}$ or as positively reacted particles within H. pylori infected hepatocytes ${ }^{[13]}$. Blood samples for the detection of $H$. pylori $\mathrm{Ab}$ were detected by measuring IgG antibody in blood samples by an Enzyme Linked Immunosorbent Assay (ELISA). Blood samples were tested for the presence of $\mathrm{IgG}$ antibodies against $H$. pylori using a quantitative ELISA (HEL-pTEST II; AMRAD, Kew, Australia). Reference standards were used to obtain a standard curve to detect $H$. pylori antibody levels in patient samples.

Statistical methods: Data were analyzed using IBM SPSS advanced statistics version 20 (SPSS Inc., Chicago, IL). Data were expressed as mean and standard or median and range as appropriate. Data were expressed as frequency and percentage. Chi-square test was used to examine qualitative variables. For quantitative data, comparison between two groups was carried out using student t-test. $\mathrm{P}$ value $<0.5$ was considered significant.

\section{Results:}

The basic histopathological features of the studied groups were summarized in Table 1. Among the whole studied groups, fifty five cases (41\%) showed positive $H$. pylori IgG $\mathrm{Ab}$ and positive $H$. pylori immunoreactivity in hepatic tissues. It was found that the mild grade of hepatitis showed the highest percent of $H$. pylori positivity $(56.3 \%)$, Figs. 1-3, followed by the moderate grade $(42.2 \%)$, then the minimal grade $(40.5 \%)$, and lastly the severe grade $(25 \%)$, with no significant difference $(\mathrm{P}$ value $=0.09)$, Table 2 . Early stages of hepatic fibrosis showed higher rate of $H$. pylori positivity (44.3\%) than that of the advanced stage of fibrosis $(37.5 \%)$. A relation that didn't reach a significant level, $\mathrm{P}$ value is 0.425 (Table 3 ), there was a directly proportional relationship between $H$. pylori positivity and the percent of steatosis, as the highest percent of $H$. pylori positivity was detected in the high grade of steatosis $(70 \%)$, Fig. 4, followed by grade $1(39.5 \%)$, then grade $0(37.2 \%)$. However, this relation didn't reach a significant level. $P$ value $=0.220$ (Table 4). The result observe that $H$. pylori infection give positive serum $\operatorname{IgG~} \mathrm{Ab}$ (without titre significant) and positive immunoreactivity in hepatic tissue and vice versa. 
Table 1: Descriptive histopathologial findings of the studied cases.

\begin{tabular}{|c|c|c|c|}
\hline & Necroinflammatory Grading & No. & $\%$ \\
\hline \multirow{4}{*}{ Stages of Inflammation } & Minimal chronic hepatitis (score: 1 - 4/18) & 37 & 27.6 \\
\hline & Mild chronic hepatitis (score: $5-8 / 18$ ) & 32 & 23.9 \\
\hline & Moderate chronic hepatitis (score 9-12/18) & 33 & 24.6 \\
\hline & Severe chronic hepatitis (score 13-18/18) & 32 & 23.9 \\
\hline \multirow{2}{*}{ Stages of fibrosis } & Early stages (score 1-3) & 70 & 52.2 \\
\hline & Advanced stage (score $4-6$ ) & 64 & 47.8 \\
\hline \multirow{3}{*}{ Steatosis degrees } & $<5 \%($ Grade 0$)$ & 43 & 32.1 \\
\hline & $5 \%-33 \%($ Grade 1$)$ & 81 & 60.4 \\
\hline & $33 \%-66 \%$ (Grade 2) & 10 & 7.5 \\
\hline
\end{tabular}

Table 2: Relation between $H$. pylori (in biopsies and IgG Ab) and necroinflammatory grade.

\begin{tabular}{|c|c|c|c|c|c|c|c|c|c|c|c|}
\hline \multirow{3}{*}{$\begin{array}{l}\text { Positive H. pylori } \\
\text { in Biopsies and } \\
\text { IgG Ab }\end{array}$} & \multicolumn{10}{|c|}{ Necroinflammatory grading } & \multirow{2}{*}{$P$ value } \\
\hline & \multicolumn{2}{|c|}{ Minimal } & \multicolumn{2}{|c|}{ Mild } & \multicolumn{2}{|c|}{ Moderate } & \multicolumn{2}{|c|}{ severe } & \multicolumn{2}{|c|}{ Total } & \\
\hline & No. & $\%$ & No. & $\%$ & No. & $\%$ & No. & $\%$ & No. & $\%$ & \\
\hline Positive & 15 & 40.5 & 18 & 56.3 & 14 & 42.4 & 8 & 25.0 & 55 & 41.0 & \\
\hline Negative & 22 & 59.5 & 14 & 43.8 & 19 & 57.6 & 24 & 75.0 & 79 & 59.0 & 19 \\
\hline Total & 37 & 100 & 32 & 100 & 33 & 100 & 32 & 100 & 134 & 100 & \\
\hline
\end{tabular}

Table 3: Relation between H. pylori (in biopsies and IgG Ab) and staging of hepatic fibrosis.

\begin{tabular}{|c|c|c|c|c|c|c|c|}
\hline \multirow{3}{*}{$\begin{array}{l}\text { Positive H. pylori } \\
\text { in Biopsies and } \\
\text { IgG Ab }\end{array}$} & \multicolumn{6}{|c|}{ Hepatic fibrosis stage } & \multirow{2}{*}{ P value } \\
\hline & \multicolumn{2}{|c|}{ Early stage } & \multicolumn{2}{|c|}{ Advanced stage } & \multicolumn{2}{|c|}{ Total } & \\
\hline & No. & $\%$ & No. & $\%$ & No. & $\%$ & \multirow{3}{*}{0.425} \\
\hline Positive & 31 & 44.3 & 24 & 37.5 & 55 & 41.0 & \\
\hline Negative & 39 & 55.7 & 40 & 62.5 & 79 & 59.0 & \\
\hline
\end{tabular}

Table 4: Relation between H. pylori (in biopsies and IgG Ab) and degree of steatosis.

\begin{tabular}{|c|c|c|c|c|c|c|c|}
\hline \multirow{3}{*}{$\begin{array}{l}\text { Positive H. pylori } \\
\text { in Biopsies and } \\
\text { IgG Ab }\end{array}$} & \multicolumn{6}{|c|}{ Steatosis degrees } & \multirow{3}{*}{ P value } \\
\hline & \multicolumn{2}{|c|}{$\begin{array}{c}<5 \% \\
(\text { Grade 0) } \\
\end{array}$} & \multicolumn{2}{|c|}{$\begin{array}{l}5 \%-33 \% \\
(\text { Grade 1) }\end{array}$} & \multicolumn{2}{|c|}{$\begin{array}{c}33 \%-66 \% \\
\text { (Grade 2) }\end{array}$} & \\
\hline & No. & $\%$ & No. & $\%$ & No. & $\%$ & \\
\hline Negative & 27 & 62.8 & 49 & 60.5 & 3 & 30 & \multirow{3}{*}{0.22} \\
\hline Positive & 16 & 37.2 & 32 & 39.5 & 7 & 70 & \\
\hline Total & 43 & 100 & 81 & 100 & 10 & 100 & \\
\hline
\end{tabular}




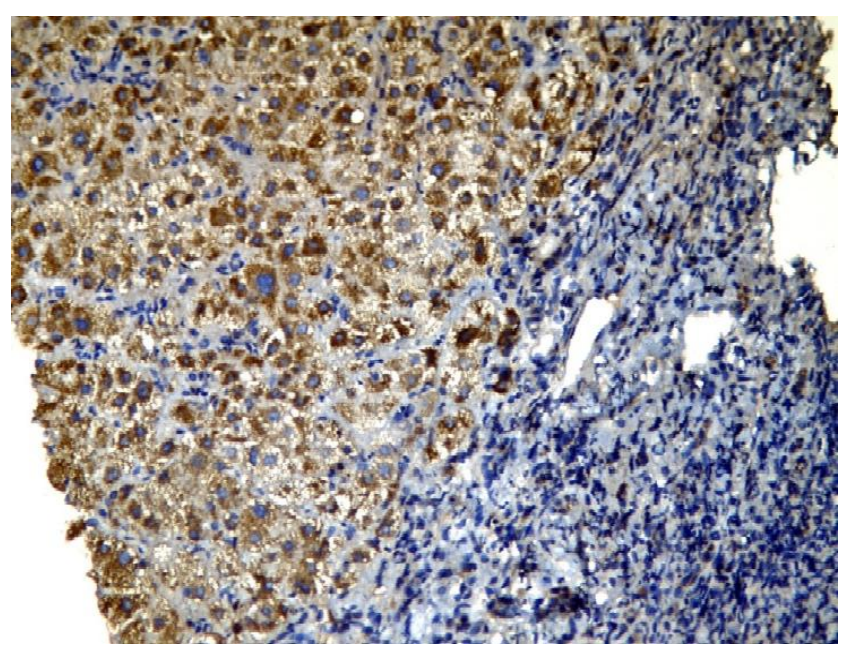

Fig. 1: Severe chronic hepatitis C showing strong, cytoplasmic, positive immunoreactivity for $H$. pylori antibody, sparing the inflammatory cellular infiltrate of the liver parenchyma (H. pylori IHC. X200).

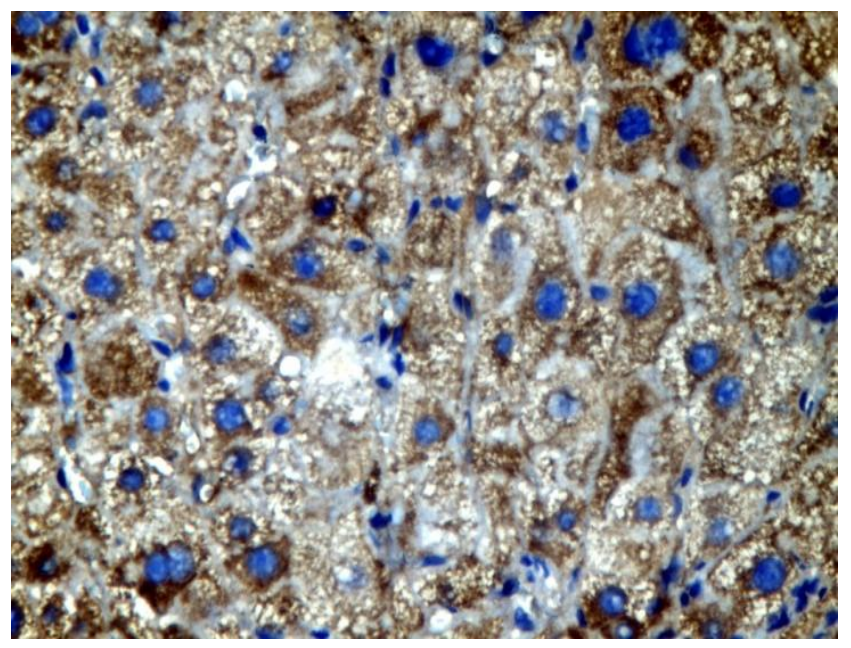

Fig. 2: Severe chronic hepatitis $\mathrm{C}$ showing strong positive of $\mathrm{H}$. pylori immunoreactivity involving mainly cytoplasm (H. pylori, IHC X1000).

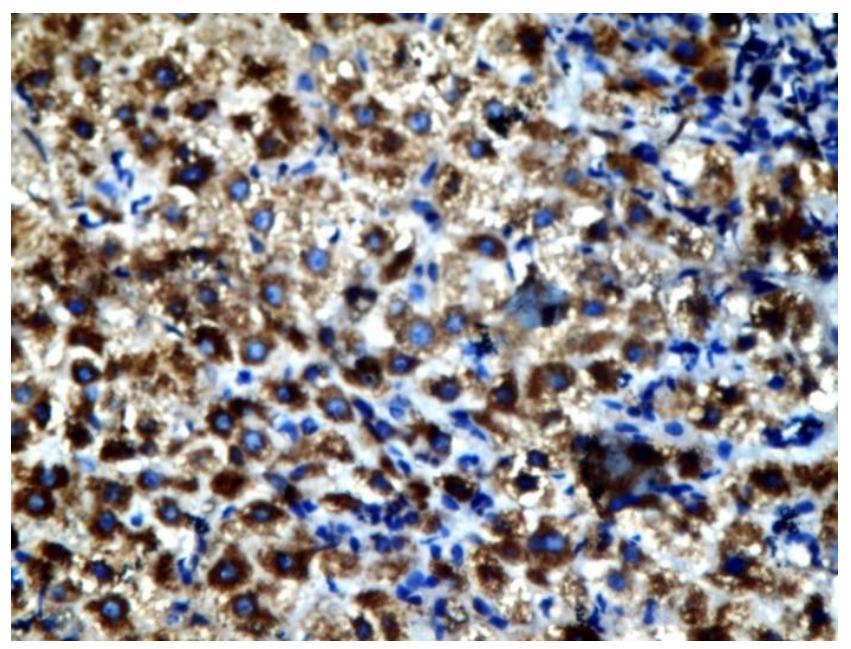

Fig. 3: Chronic hepatitis-C-biopsy showing strong positive immunoreactivity for $H$. pylori, involving the hepatocytic cytoplasm and not involving the infiltrating inflammatory cells (arrow) (H. pylori, IHC X400). 


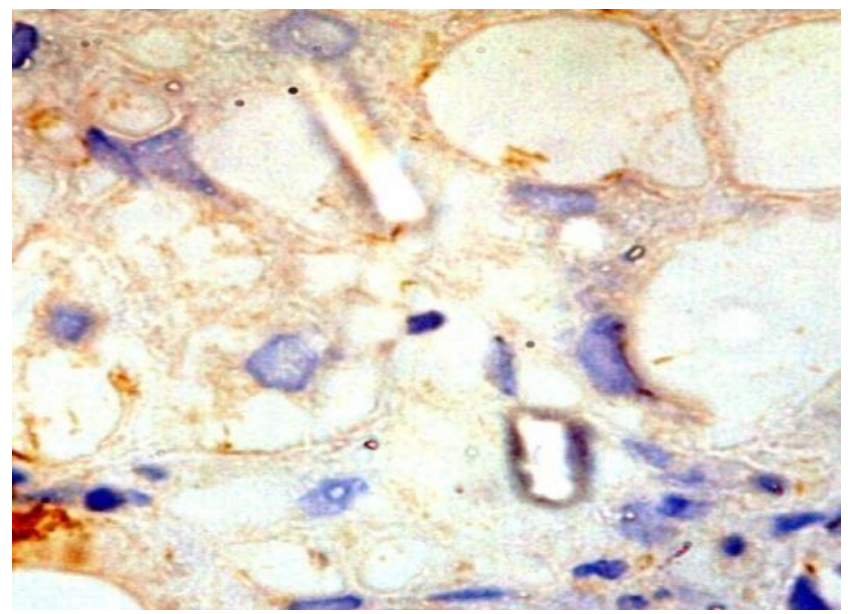

Fig. 4: Liver biopsy of chronic hepatitis $C$ patient with macrovesicular steatosis, showing the immunoreactive bacilli inside the dissolved hepatocyte intracytoplasmic lipid-vacuoles (H. pylori, IHC X1000).

\section{Discussion}

Infection with $\mathrm{HCV}$ and $H$. pylori is a global health problem. The claimed possible relationship between both organisms is always considered a valuable issue in clinical research. Several studies have shown that immunohistochemical staining with specific $H$. pylori antibodies shows the highest sensitivity and specificity in detecting $H$. pylori ${ }^{[14]}$. $41 \%$ of the our study population showed positive $H$. pylori infection, similar to those reported in Polish study over 97 chronic HCV patients who were examined using immunohistochemical aiding for their liver biopsies searching for $H$. pylori antigens which were found in $41 \%$ of those patients ${ }^{[15]}$, slightly lower levels $(30 \%)$ were observed in one study ${ }^{[16]}$ and slightly higher (50 $\%)$ in another study ${ }^{[7]}$. In a study using genus specific nested PCR as a different method for $H$. pylori detection in the liver cells, much lower prevalence was detected reached $11.5 \%$ of examined liver biopsies ${ }^{[17]}$. Many studies tried to build a cogent relation between presence of $\mathrm{H}$. pylori in hepatocytes and its role in progression of $\mathrm{HCV}$ related necroinflammatory process involving the hepatocytes which could explain to certain extent the rapid progression of the disease in some cases and the modest progression in other cases. In this series of patients a heavy expression of $H$. pylori infection was found in cases with mild necroinflammatory grade and the lease expression in cases with severe necroinflammatory grade $(56.3 \%, 25 \%$, respectively) these results flip over this hypothesis which was agreed by Esmat et al. ${ }^{[9]}$ who did their study by examining liver samples for the presence of H. pylori DNA by PCR on the liver tissue specimens of Egyptian patients, found that the positivity of $H$. pylori was directly proportional to the severity of the liver pathology, this being $75 \%$, $52 \%$ and $32 \%$ in severe, moderate and mild grades, respectively ${ }^{[9]}$, a deny of this theory was declared by French group ${ }^{[18]}$ who showed no significant association between $H$. pylori positivity and necroinflammatory grade.
Passing into a parallel line in this study, H. pylori was found to a great extent in those with early fibrosis and to a small extent in patients with advanced fibrosis degrees $(44.3 \%, 37.5 \%$ respectively), contrary to these results the French group ${ }^{[18]}$ found that positive cases of $H$. pylori tended to be higher in $\mathrm{HCV}$ patients with cirrhosis $(41.6 \%)$ than in those without cirrhosis (17\%) or controls (15.4\%). Another study reported that $61-68 \%$ of cirrhotic liver tissue showed positive $H$. pylori in comparison with $4.5 \%$ and $3.2 \%$ of hepatitis patients with early stages of fibrosis and controls, respectively ${ }^{[18]}$ while many reports agreed ${ }^{[9.17,19]}$.

Interestingly, we observed a direct proportional relationship between the $H$. pylori positivity and the degree of steatosis, the highest number was detected in patients with grade 2 steatosis $(70 \%)$ followed by grade $1(39.5 \%)$ then grade $0(37.2 \%)$. This relation may represent also a relevant bond between $H$. pylori infection and its related inflammatory cytokines, with hepatic steatosis being a major face for metabolic syndrome. In this study we observed that all positive $H$. pylori immunoreactivity gave positive $\operatorname{IgG} \mathrm{Ab}$ and all negative H. pylori immunoreactivity gave negative IgG $\mathrm{Ab}$.

In spite of this wide range of diversity in these observations, most of the published studies on $\mathrm{H}$. pylori detection in HCV hepatic tissue revealed that $H$. pylori is expressed in HCV cases. So, it seems clear its possible role, if ever, in progression of liver disease and pathogenesis of cirrhosis which is the most common cause of hepatic decompensation and malignancy of chronic HCV patients ${ }^{[20]}$.

\section{Conclusion:}

Helicobacter pylori could be detected in the blood and in the liver tissue of chronic HCV patients giving the same results, however in the present work; its presence was neither associated with advanced liver inflammation nor the fibrosis processes. This detects the importance of $H$. pylori $\operatorname{IgG} \mathrm{Ab}$ to dispense with biopsies. The investigation of the pathological role of $H$. pylori 
colonization in the liver tissue and in serum of patients with $\mathrm{HCV}$ is an important and valuable task, as progress that made in this area will increase our understanding of the aetiopathology of $\mathrm{HCV}$ and its inflammatory process progression, and it may eventually be possible to prevent or arrest complications by the use of antibiotics or vaccinations, especially if treatment started early.

\section{References}

1) Marchildon, P., Sugiyama, T., Fukada, Y., Peacock, J., Asaka, M., Shimoyama, T. and Graham, D. (2003). Evaluation of the effects of strain-specific antigen variation on the accuracy of serologic diagnosis of Helicobacter pylori infection. J. Clin. microbiol. 41:1480-1485.

2) Hoang, T., Wheeldon, T., Bengtsson, C., Phung, D., Sörberg, M. and Granström, M. (2004). Enzyme-linked immunosorbent assay for Helicobacter pylori needs adjustment for the population investigated. J. Clin. microbiol. 42:627630.

3) Malfertheiner, P., Megraud, F., O'morain, C., Atherton, J., Axon, A., Bazzoli, F., Gensini, G., Gisbert, J., Graham, D. and Rokkas, T. (2012). Management of Helicobacter pylori infection-the Maastricht IV/Florence consensus report. Gut 61:646-664.

4) El-Masry, S., El-Shahat, M., Badra, G., AboelNour, M. and Lotfy, M. (2010). Helicobacter pylori and hepatitis $\mathrm{C}$ virus coinfection in Egyptian patients. J. Glob. Infect. Dis 2:4.

5) Pellicano, R., Mazzaferro, V., Grigioni, W., Cutufia, M., Fagoonee, S., Silengo, L., Rizzetto, M. and Ponzetto, A. (2004). Helicobacter species sequences in liver samples from patients with and without hepatocellular carcinoma. World J. Gastroenterol. 10:598-601.

6) Fagoonee, S., Pellicano, R., Rizzetto, M. and Ponzetto, A. (2001). The journey from hepatitis to hepatocellular carcinoma. Panminerva Med. 43:279-282.

7) Pirouz, T., Zounubi, L., Keivani, H., Rakhshani, N. and Hormazdi, M. (2009). Detection of Helicobacter pylori in paraffin-embedded specimens from patients with chronic liver diseases, using the amplification method. Digest Dis Sci. 54:1456-1459.

8) El-Omar, E., Carrington, M., Chow, W., McColl, K., Bream, J., Young, H., Herrera, J., Lissowska, J., Yuan, C. and Rothman, N. (2000). Interleukin1 polymorphisms associated with increased risk of gastric cancer. Nature, 404:398-402.

9) Esmat, G., El-Bendary, M., Zakarya, S., Ela, M. and Zalata, K. (2012). Role of Helicobacter pylori in patients with HCV-related chronic hepatitis and cirrhosis with or without hepatocellular carcinoma: possible association with disease progression. $J$ Viral Hepat. 19:473-479.

10) Ishak, K., Baptista, A., Bianchi, L., Callea, F., De Groote, J., Gudat, F., Denk, H., Desmet, V.,
Korb, G. and MacSween, R. (1995). Histological grading and staging of chronic hepatitis. J Hepatol. 22:696-699.

11) Kleiner, D., Brunt, E., Van Natta, M., Behling, C., Contos, M., Cummings, O., Ferrell, L., Liu, Y., Torbenson, M. and Unalp-Arida, A. (2005). Design and validation of a histological scoring system for nonalcoholic fatty liver disease. Hepatology 41:1313-1321.

12) Cartun, R., Kryzmowski, G., Pedersen, C., Morin, S., Van Kruiningen, H. and Berman, M. (1991). Immunocytochemical identification of Helicobacter pylori in formalin-fixed gastric biopsies. Mod Pathol. 4:498-502.

13) Goo, M., Ki, M., Lee, H., Yang, H., Yuan, D., Hong, I., Park, J., Hong, K., Han, J. and Hwang, O. (2009). Helicobacter pylori promotes hepatic fibrosis in the animal model. Lab Invest. 89:12911303.

14) Riba, A., Ingeneri, T. and Strand, C. (2011). Improved histologic identification of Helicobacter pylori by immunohistochemistry using a new Novocastra monoclonal antibody. Lab Med. 42:3539.

15) Stalke, P., Abu Al-Soud, W., Bielawski, K., Bakowska, A., Trocha, H., Stepinski, J. and Wadström, T. (2005). Detection of Helicobacter species in liver and stomach tissues of patients with chronic liver diseases using polymerase chain reaction-denaturing gradient gel electrophoresis and immunohistochemistry. Scand J Gastroenterol. 40:1032-1041.

16) Ren, F., Chen, Y., Wang, Y., Yan, Y., Zhao, J., Ding, M., Zhang, J., Jiang, Y., Zhai, Y. and Duan, Z. (2010). Comparative serum proteomic analysis of patients with acute-on-chronic liver failure: alpha-1-acid glycoprotein maybe a candidate marker for prognosis of hepatitis B virus infection. J Viral Hepat. 17:816-824.

17) Mahmoud, M., Elden, L., Awad, M. and Haile, H. (2011). Helicobacter pylori DNA in Liver Tissues From Chronic Hepatitis C Egyptian Patients. Gastroenterol Res. 4:262.

18) Castera, L., Pedeboscq, A., Rocha, M., Le Bail, B., Asencio, C., de Ledinghen, V., Bernard, P., Laurent, C., Lafon, M. and Capdepont, M. (2006). Relationship between the severity of hepatitis $\mathrm{C}$ virus-related liver disease and the presence of Helicobacter species in the liver: a prospective study. World J. Gastroenterol. 12:7278.

19) Rocha, M., Avenaud, P., Menard, A., Le Bail, B., Balabaud, C., Bioulac-Sage, P., de Magalhaes Queiroz, D. and Megraud, F. (2005). Association of Helicobacter species with hepatitis C cirrhosis with or without hepatocellular carcinoma. Gut 54:396-401.

20) Queiroz, D., Rocha, A., Rocha, G., Cinque, S., Oliveira, A., Godoy, A. and Tanno, H. (2006). Association between Helicobacter pylori infection and cirrhosis in patients with chronic hepatitis C virus. Digest Dis Sci. 51:370-373. 